\section{Contributors}

Elizabeth Elsey

Miss Elizabeth Elsey is an ST2 in Nottingham working in surgery. She spent 4 months in general practice as an FY2 and is one of the new breed of doctors to survive the changes to training over recent years. lizzy.elsey@tiscali.co.uk

John Frey thought that the US would come to its senses and implement a national health system with universal national health system with universal coverage since he was a medical
student in 1968. Meanwhile he hopes student in 1968. Meanwhile he hopes year in the NHS 28 years ago continues to inspire him that it can be done right, somewhere. jfrey@fammed.wisc.edu

Stanley Jeffs says: 'In my life I think I have met the best doctors it is possible for the medical profession ever to produce, and also the worst the absolute dregs. Both are the exceptions. Most of us just do a good job, and that is how it should be.'

stanleyjeffs@yahoo.co.uk

A Kaufman is Vice President for A Kaufman is Vice President Department of Family and Community Medicine at the University of New Mexico, Albuquerque, US. akaufman@salud.unm.edu

Jan De Maeseneer is the Head of Department of Family Medicine and Primary Health Care, Ghent University, Belgium.

jan.demaeseneer@ugent.be

Nigel Mathers is Chair of Primary Medical Care and of Clinical and Research for the RCGP and is based at the Academic Unit of Primary Medical Care, School of Medicine and Biomedical Sciences, University of Sheffield. He is a GP in Sheffield who believes that self management of both complex multimorbid conditions and $\mathrm{mind} / \mathrm{body}$ interactions are key mind/body interactions are key components of successful general
practice - this belief was central to practice - this belief was central to
the successful completion of his the successful completion of his recent charity cycle ride from
to Paris!

N.Mathers@sheffield.ac.uk

Shabir Moosa is a senior lecturer at the Department of Family Medicine, University of Witwatersrand, University of Witwatersrand,
Johannesburg, South Africa. moosasah@medicine.wits.ac.za

Nicola MR Perrin is a Senior Policy Adviser at the Wellcome Trust n.perrin@wellcome.ac.uk

Yongyuth Pongsupap is a Primary care component manager of Health Care Reform Project, and Expert of Health Policy and Planning Bureau, National Health Security Office, Nonthaburi, Thailand. Nonthaburi, Thailand.
pongsupa@health.mpoh.go.th

\section{Ann Richardson}

a.richardson@|se.ac.uk

Meg Thomas is a GP in Newbury, West Berkshire.

thommeg@googlemail.com

Graham CM Watt is Norie Miller Professor of General Practice at the University of Glasgow, on behalf of Heads of UK University Departments of General Practice and Primary Care gcmw1j@clinmed.gla.ac.uk

\title{
Coastal views
}

It's a tricky one, I am thinking. We have recently more-or-less completed an overhaul of the surgery interior. Uncomfortably close to Magnolia in places perhaps, but at least we have moved away from the palette provided by our mother ship, the local NHS hospital.

'Well, me catheter started leakin'...' starts off the rather unhappy old gent in the stackable chair facing me.

Gone are rooms of Bile Green, Jaundice Yellow, and Cyanosis Blue. It all looks rather more emollient now, albeit not quite Conran still. Perhaps that is because we retain some of the furniture from Viking Direct.

'... so me son got some plastic bags to put on me armchair to stop it all sinkin' in too much ...' he continues, determinedly using up more than a fair allocation of time for his opening gambit.

True, we still have vertical blinds, which give a rather office feel to the windows, but then it is helpful to have patients feel they can strip in relative privacy when about to be examined. Not that most seem to care whether the blinds are open or closed. Anyway, we have kept the old curtains. Washed and refreshed, they look homely.

Mistaking my vacant stare for a nonverbal continuer, my sad old patient is moaning still, his story not yet complete. 'Everythin' stank of urine,' he exclaims, 'everythin'.'

He pauses as though at an end, but before I can withdraw myself from my musings he plunges on again with his absorbent tale. 'I tried ringin' for the narse but she had to come all the way up from Newcastle, or mebbe the car did, but anyways it took 2 hours to get her here. She cleaned us up right enough but then told us the catheter was alreet and to see how I went till Monday ...'

The carpets are more of an issue. Deep pile was never going to be an option due to the number of patients we have who are flaky, leaky, pukey, or just still wearing their work-boots fresh from the fields. Nevertheless I maintain we did right to retain carpets, even if they are harsh fibred and sometimes orange (ochre is the word we use now). We run against the grain of modern infection control theory in retaining any textured surfaces, but carpets are more welcoming than linoleum so perhaps in days of Access and Choice this is a poorly recognised Catch-22.

'Then I was wet again,' voiced with emphasis, 'but me son had already been sent to get us. You could tell the ward staff wanted us to go, so I was discharged anyways. After 3 weeks it should have been sorted but I still think they shouldn't have made us go home like that.' $\mathrm{He}$ pauses again, and I vaguely wonder whether I have missed the punchline yet or not.

Once more he resumes his careful narrative. 'There was nowt in the fridge neither, so me son had to do some shoppin' for us ...'

Wall cover: that is how an acquaintance in the hotel trade once referred to pictures and the like. The waiting room has its noticeboards. Nobody reads them. The rest of the walls are rather gaping in their emptiness. So what should we do? Go back to the old ways and put up NHS campaign posters everywhere, the sort that curl and tear and fade and infection control people like?

'... me catheter had leaked again ...' he says, and I realise I have lost count of how many times. I sense we are drawing closer to today in our saga now though: it is not yet time to despair. '.. and the nurse said I was conspitated ...'

Or should we, at a time when our income is falling, heed the advice of art therapists and go beyond noticeboards and faded old posters contaminated with MRSA? Even beyond photographs of the doctors' families taken on fancy holidays? To mentally soothing art?

Yes! I think, let me persuade them to have art: local art, rural art, coastal art. uplifting art!

'So I've been much betta since she gave us that anenome.'

A wave of warm companionship sweeps over me as I realise we have been on the same tack all along.

DOI: 10.3399/bjgp08X342778 